\title{
An ecology and economy combined carrying capacity model for sustainable tourism development
}

\author{
S. M. Lee \\ Dept. Leisure Tourism Development, College of Tourism Science, \\ Kyonggi University, Korea
}

\begin{abstract}
In the present study, an ecology and economy combined model is presented for scientific and quantitative assessment of sustainable tourism development. In the ecological module, two contrast lines are introduced to estimate an ecological carrying capacity at their intersection: ecological damage loading line and recovery capacity line, while in the economic module, a market-based economical carrying capacity is determined at the intersection of marginal benefit of visitor consumption line and marginal cost of environmental goods line, which provides a maximum total net profit. To achieve a sustainable tourism management, the ecological carrying capacity should be enhanced to keep step with increasing demand of economical carrying capacity. Therefore, this study also presents a combined assessment process composed of D-P-S-I-R process of ecological assessment and D-B-M-P-R process of economical assessment based on the present combined model, and further discusses the social reduction of damage loading rate and the technical improvement of recovery capacity of ecosystem to allow the surplus capacity. As a case study, the proposed concept has been applied to Suncheon City in which the Suncheon Bay Ecological Park is located. The park is an extremely unique saltwater wetland in the Korean Peninsula and thus designated as a preservation area in the light of ecological regeneration and protection.
\end{abstract}

Keywords: D-P-S-I-R, D-B-M-P-R, damage loading, recovery capacity, environmental goods, Suncheon Bay, ecology and economy combined. 


\section{Introduction}

Globally, tourism is developing as the national tourism competitiveness and growth driving force industry that performs the key role of the economy, and is displaying great influence on the regional society and economy. As the popularity of coastal and marine areas for tourism and recreation continues to increase, concerns have been raised that additional use could damage the ecological integrity of resources, reduce the quality of user experiences, depreciate the condition of facilities accommodating users, and generate conflict among interest groups (Lück [1]; Manning [2, 3]; Orams [4]). However, the concept of sustainable development is a rather vague nonoperational definition's attempt to understand and define more precisely the meaning of sustainable development, which requires a suitable quantification in socio-economic, cultural and scientific terms (Marques et al. [5]).

Regulatory agencies face a number of challenges in this context as they attempt to implement appropriate management strategies that mitigate social, environmental, cultural, and facility impacts of increasing public use to ensure that user satisfaction and environmental and facility conditions do not deteriorate (Ryan [6]).

Environmental preservation depends on the assessment of environmental effects concerning the establishment of current tourism site developments. In other words, there has not yet been a proposal of a method that can include the details of, or does not include the details on the damage based on tourism behaviors that can induce further environmental damage by constantly allowing visitors.

Accordingly, this study has revealed the existence of the limit on the market carrying capacity that produces the optimum social profit, and the existence of the minimum limit ecological carrying capacity for ecological recovery, through the establishment of a sustainable concept that is based on the economic profit and ecological recovery concerning tourism sites and tourism resources developed in the coast through the proposal of a limit-control carrying capacity assessment model as a practical tool based on the development of tourism sites by analyzing the environmental and ecological limit carrying capacity indicator and environment economical limitation carrying capacity indicator, based on the proposal of the detailed concept of sustainable tourism development based on existing studies. Accordingly, the ECC(Ecological Carrying Capacity Limit) is calculated from the contaminate substance demand curve of the ecological recovery capacity, and the supply curve of the ecological damage capacity, and the MCCL(Market Carrying Capacity Limit) is calculated from the demand curve of tourism profit, and the supply curve of the environmental material cost.

As in all models, this model also has an indicator newly implemented together with the existing indicator used to judge the sustainability. This study is to examine the definitions and properties of these indicators, and to discuss the detailed measures of indicator management of a virtuous cycle that optimally secures usage consumption for the preservation and the economical and sustainable use of coastal tourism resource, by proposing a methodology that 
quantitatively assesses the limit of the carrying capacity that allows the coastal ecological tourism resources and the tourism business market to be sustainable in our generation as well as in future generations.

This study allows the operation of an integrated coastal management program that is more detailed and practical and contributes to the establishment of a sustainable model of leisure tourism and coastal ecology by proposing an expanded concept of carrying capacity of a virtuous profit structure from the relationship between the ECCL and the MCCL. This study also proposes an assessment model system that realizes a sustainable coastal ecological tourism of a virtuous cycle with the use of the D-P-S-I-R system and the D-B-M-P-R system in order to sustain the coastal ecological tourism and leisure tourism development plan as a virtuous economical structure.

\section{Carrying capacity model of sustainable and virtuous profit structure}

\subsection{Sustainable environmental preservation and economic profit model}

A model is a system that is adopted in scientific or logical theories for the explanation of certain phenomenon or effects, which is formed to physically or numerically manifest the main properties of the subjects by systemizing them in order to simplify the analysis and evaluation of complicated systems. The basic structure of a model are composed of an input and output system, and the evaluation model is a structure arranged to calculate specific phenomenon or effects of the subjects as output, which are deduced as the change of input, together with the development plans or monitoring data.

Accordingly, the environmental effect assessment system applies the existing D-P-S-I-R system (Driving forces-Pressure-State-Impact-Response framework) and the similarly progressed economic profit assessment system is composed of the D-B-M-P-R system (Development-Business-Market-Profit-Response frame work). The economic profit assessment system which is newly proposed in this study, has a model structure that allows the development of a virtuous profit structure that guarantees maximum economic profit and environmental preservation, in order to obtain universal preference based on the concept of sustainable development.

Figure 1 displays the framework of analyzing sustainability, which evaluates each model by linking them with one another. The framework allows tuning for sustainability concerning economic growth and environmental preservation in the S (state) level of the environment and the $\mathrm{M}$ (market) level of the economy. In other words, it is a methodology that assesses the sustainability of development plans by scientifically and systematically considering the environment, as well as the economy, in correspondence with the purpose of sustainable tourism development by avoiding the contradiction of applying the existing environmental assessment in the assessment of the tourism development industry. Furthermore, the responses following the results of the two models are 


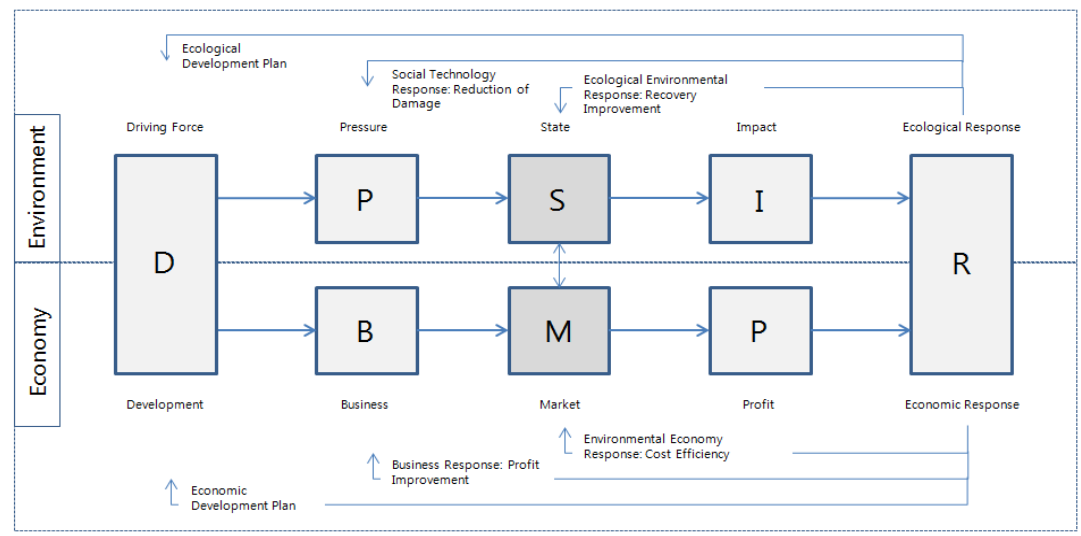

Figure 1: The combined structure of D-P-S-I-R of the ecological environment and D-B-M-P-R of the environmental economy.

also formed in each aspect of the environment and the economy based on the evaluation process.

\subsection{Ecological carrying capacity model}

A model that uses two conflicting indicators: the damage capacity indicator based on the act of natural damage through the use of the environment by tourists, and the ecological recovery strength indicator related to natural preservation characteristics, has been proposed by Lee [7], and its model has been applied for the estimation of the ECCL on Suncheon Bay by Lee [8], thus this study is to briefly introduce its theoretical concept. This model allows the estimation of the carrying capacity limit at the point where the demand curve and the supply curve, known as the two conflicting recovery capacity and damage capacity meet. The model has been developed with the purpose of apprehending the influential relationship of the increase in the number of tourists on the applying site.

If an excessive amount of tourists exceeds the limit of use demand to a sustainable tourism site, it can degenerate as a non-sustainable tourism site where greater environmental damage occurs than recovery. In other words, if the use demand exceeds the carrying capacity limit due to the unmanageable control, it may lead to the result of damage on the tourism resources or tourism site, ultimately leading to the closing of the site.

Accordingly, in order to avoid the extreme situation of the tourism site ultimately coming to a close due to excess the ECCL, the collection and treatment of environmentally harmful substances that occur due to the stay and activities of excessive tourists, and artificial measures such as ecological education is needed. This is the recovery process that artificially increases the capacity when the environmental capacity is naturally reached. This stage requires the consideration of the development of a sustainable tourism site. 
The increase of the carrying capacity may be needed in order to develop tourism resources and a tourism site of a virtuous cycle, and as shown in fig. 2, the carrying capacity limit can be increased by improving the recovery capacity or reducing the environmental damage capacity.

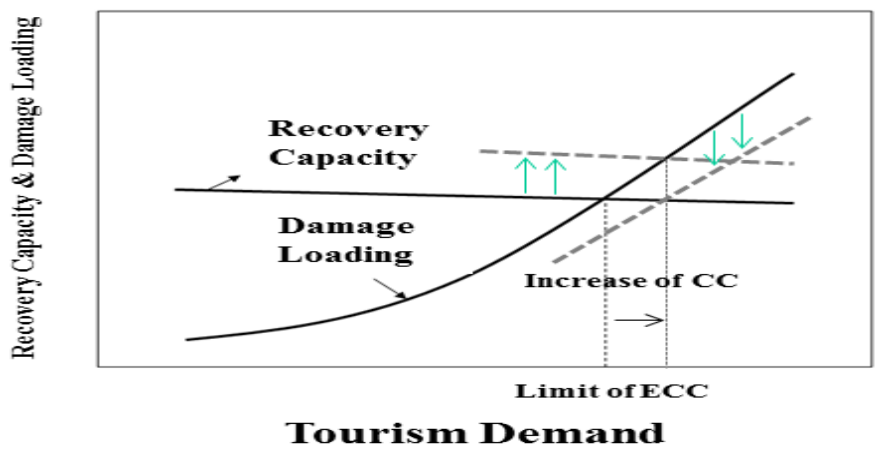

Figure 2: $\quad$ Increase of carrying capacity (Source: Lee [8]).

With the method of decreasing the environmental damage capacity, there are educational methods, but a proposal of a development methodology that sustains the ecological recovery capacity from damage and minimizing damage concerning the development of a tourism site is needed. Furthermore, there is a need for a tourism site development plan that can improve the artificial recovery strength with low cost. Accordingly, for sustainable tourism development, the quantitative tourism must change into qualitative tourism through the management of the carrying capacity, and a development strategy through the management of a sustainable indicator is needed for this change.

Firstly, a management that can reduce the sustained occurrence of damage, secondly, the preserved management of the ecological recovery capacity, and thirdly, the optimum management of the artificial recovery capacity is needed.

If a tourism site is planned in a way that enhances the environmental recovery capacity, the tourism site will secure greater use demand as a sustainable tourism site. Accordingly, there is a need for a developmental process that proceeds through a mutually virtuous supplementary stage in order to achieve a plan composed to improve the environmental recovery strength for enhanced carrying capacity through the process of predicting the use demand that allows the continuation of economic activities, and the process of assessing the carrying capacity for the continuation of the ecological environment.

\subsection{Virtuous profit structure model}

\subsubsection{The concept of environmental goods}

Existing economic theories regard the environment to be able to process unlimited amounts of various contaminate sources and that unlimited natural resources are extracted and implemented into the economy. The current coastal 
tourism site development pursues the positive effect of economic convenience, and does not consume the costs of social and environmental damage, thus the problem of environmental damage is continually accumulated in the region and ultimately becomes a burden in the regional society, unlike the developer, thus leading to other problems and is also unable to be economically sustained.

Most environmental problems are problems caused by the accumulation of economic activities performed under such economic principles, hence environmental damage costs occur due to the externalities that are not appropriately reflected in the market price (Pigou [9]). The most effective way of reducing double environmental damage under the preservation of economic activities of the same production and consumption scale is to increase the proportion of recycling. However, all these cannot be resolved with economic activities performed under economic principles, thus the costs of economic damage that will occur on the future generation is assessed as environmental goods and an effort to reflect this on the economic structure of the current market is being pursued.

When environmental reproduction strength is considered concerning sustainable economic growth, market control based on the concept of environmental goods allows economic growth to avoid the extreme situation of the limits of growth (Meadows et al. [10]) and when a tourism site is developed by reflecting environmental goods to allow sustainable economic growth where the harmony of preservation and growth is possible, the recycling of waste can secure economic efficiency, thus significantly reducing double environmental damage based on the waste and extraction of resources. The government's attempt that pursues the change in the economic structure of an environmentally friendly market with the implementation of the concept of environmental goods when planning or developing such a tourism site performs a positive role, which includes the tax policies as the Pigouvian tax.

\subsubsection{Pricing of environmental goods}

In the market, market goods are traded with price, adjusted by demand and supply, used as the medium. Demand is a concept that reflects profit, and supply is a concept that reflects cost. Similarly, the price of environmental goods is also determined based on the market principle adjusted by demand and supply. In other words, the marginal environmental cost based on the supply of environmental goods increase and the restrictive social convenience based on the demand of environmental goods decrease.

The optimization of a socially efficient distribution of environmental goods is determined by the price $(\mathrm{P})$ of environmental goods and is achieved by the amount of emission (Q) with the same degree of marginal cost based on supply and restrictive convenience based on demand, as shown in fig. 3a. Therefore, in order to produce this result, the market price of environmental goods must fully reflect the expense of the entire society based on the environmental damage from the production of the goods or its use enjoyed by the entire society. If not, it will cause market failure based on environmental goods as many scholars anticipate. In order to faithfully reflect the cost of damage based on the production of goods 
in the market economy, or the convenience benefited from the goods, a valuation of the environmental goods through the analysis of cost and convenience is needed. When environmental goods are reflected as so, the financial burden grows with increased number of visitors, it thereby displays the existence of a limit that produces maximum profit without the unlimited growth of social profit based on the number of visitors. However, this limit refers to the limit that produces the maximum profit concerning the environmental economy, thus differs from the ECCL that guarantees the sustainability of the ecological system.

The concept of ECCL for ecological tourism sites has already been proposed. In other words, the limit carrying capacity of tourists that does not allow the ecological damage capacity to exceed the ecological recovery capacity concerning the recovery capacity of the ecological environment has been introduced in fig. 3(a). Furthermore, in order to sustain the damage capacity that applies to this limit carrying capacity, the re-establishment (fig. 3(b)) of the environmental damage curve that suppresses the maximum amount of permitted emissions is needed, so that the ecological damage capacity does not exceed the ecological recovery capacity concerning environmental economy. For convenience, the ecological system has been regarded as being sustained as long as the permitted amount of emissions is not exceeded, thus putting damage at zero. Accordingly, if the price of environmental goods adjusted with the more steep increase is applied as shown in (fig. 3(b)), a limit of the amount of emission is provided, which permits more number of visitors, hence is able to establish a virtuous ecological tourism cycle that is sustainable through the expansion of profit.
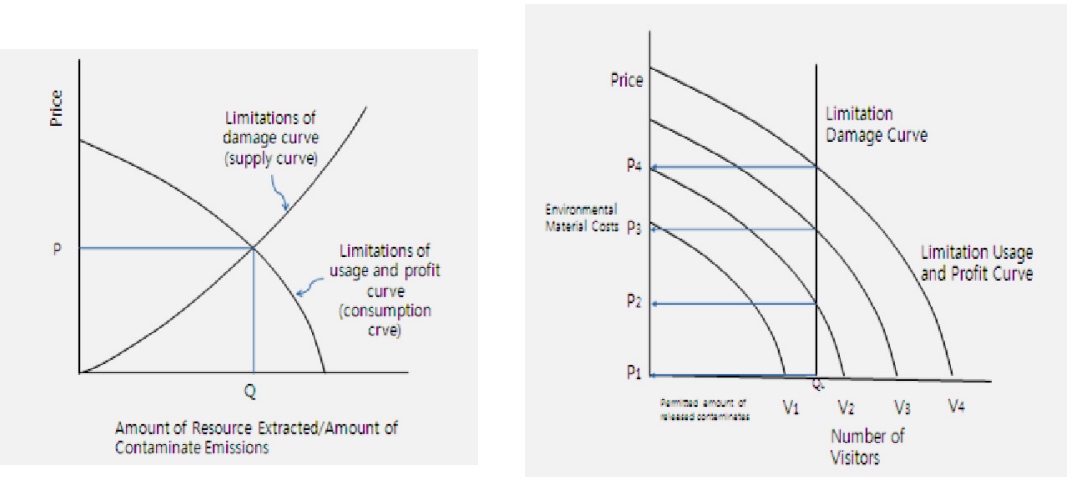

Figure 3: The conceptual diagram on (a) the price of environmental resources (P) and (b) the limit to emissions of environmental resources.

Figure 4 displays the environmental goods cost curve that reflects the adjusted price of environmental goods as shown in fig. 3(b), with visitors exceeding the ECCL. Displaying the accumulated cost of environmental goods when the maximum allowance of emissions, The MCCL in fig. 4 exceeds the ECCL thus is unable to depend on natural recovery strength. Therefore, in order to achieve sustainable ecological tourism, the corresponding cost of environmental goods 
(shadow zone A in fig. 4) is consumed to confine the amount of emissions as shown in fig. 3(b) or additional cost is consumed to artificially increase the recovery capacity in order to purify additional emission of contaminates. In this study, an optimum profit structure of an environmentally and economically virtuous cycle is seen as being established, within the lines to guaranteeing sustainable ecological tourism based on the concept of ECCL.

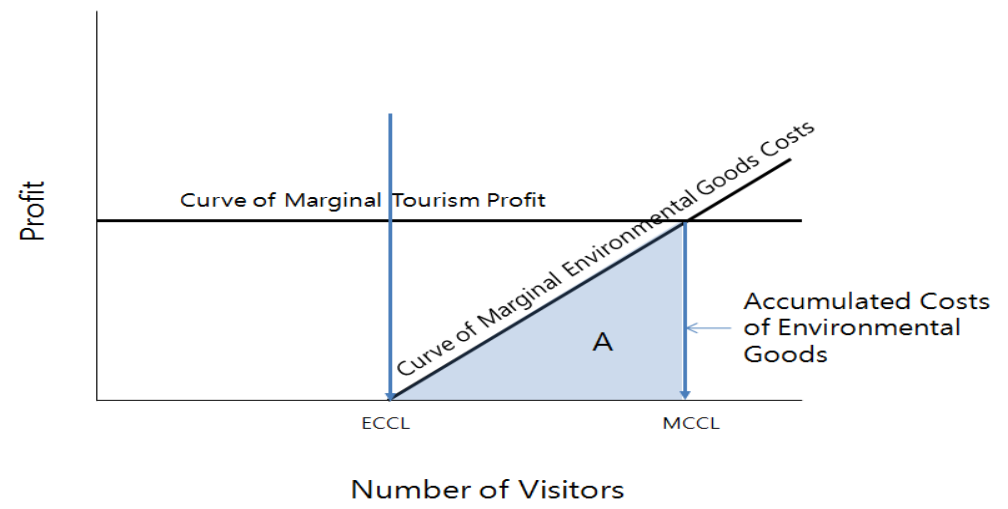

Figure 4: The accumulated cost of environmental goods based on the limited amount of emission.

\section{The combination and application of the models}

In order to first approach the problem of sustainability in a scientific aspect, a methodology that pursues the balance of development and damage must be established. The sustainable development mimetic diagram of Adams [11] has been changed from a three-column model to a two-column model system of economic development and environment preservation, in order to apply the concept of balance. As a parameter that deduces the balance of both sides, known as social welfare, it performs the role of pursuing profit with the social use of the environment and of pursuing a comfortable environment based on qualitative life.

As depicted in fig. 5, two conflicting factors exist in the environment model and the economy model, which are environmental preservation and social use in the environment model, and economic profit and social cost in the economy model. The preservation of the environment is close to the recovery capacity, which is the usage consumption scale of the environment ecology, and the environmental usage of the society if close to the damage capacity, which is the contaminate supply scale. The damage capacity is the input, as it is relevant to pressure $(\mathrm{P})$ in the ecological environment evaluation system, and the recovery capacity is a system that displays the ecological state (S). The profitability of the economy is close to the profit of tourism, which is the business consumption scale of the tourism market, and the recovery cost of the society is close to the 
environmental resource cost, which is the environment supply scale of the ecological tourism market. Profit from tourism is input that is relevant to business (B) in the environmental economic evaluation system, and the cost of environmental resources is the system that displays the state $(\mathrm{S})$ of the ecological tourism market.

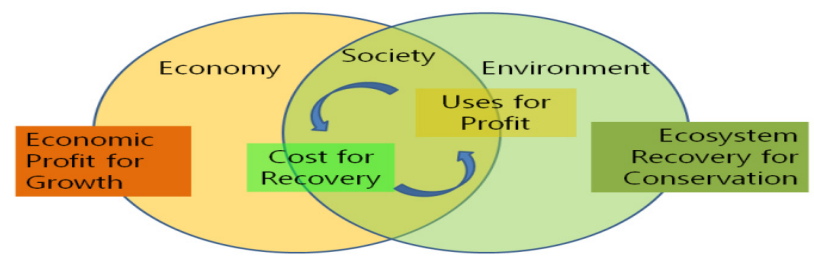

Figure 5: Two-column model of the sustainable economic growth and environment preservation.

This chapter proposes the method of enhancing the limits of carrying capacity strength to improve the recovery capacity of the artificial ecological and the reduction of the damage capacity on the ecological system with the use of the cost of environmental resources, for the sustainability of the ecological tourism development as a virtuous circle. In other words, it allows sustainability concerning the ecological and also allows the carrying capacity of tourists, which is a virtuous circle concerning the environmental economy. This refers to the enhancement of tourist satisfaction, the quality of life and the welfare of regional residents, and the optimization of economic profit through qualitative changes within limits of carrying capacity. A careful selection is needed as the artificial expansion of the limitations carrying capacity for the pursuit of economic profit can be accompanied by problems that are difficult to control, such as diverse damage on ecospecies, secondary environmental problems, and limitations of management. The organization of the determination process for the carrying capacity tourists in virtuous circular and sustainable ecological tourism is as shown in fig. 6 .

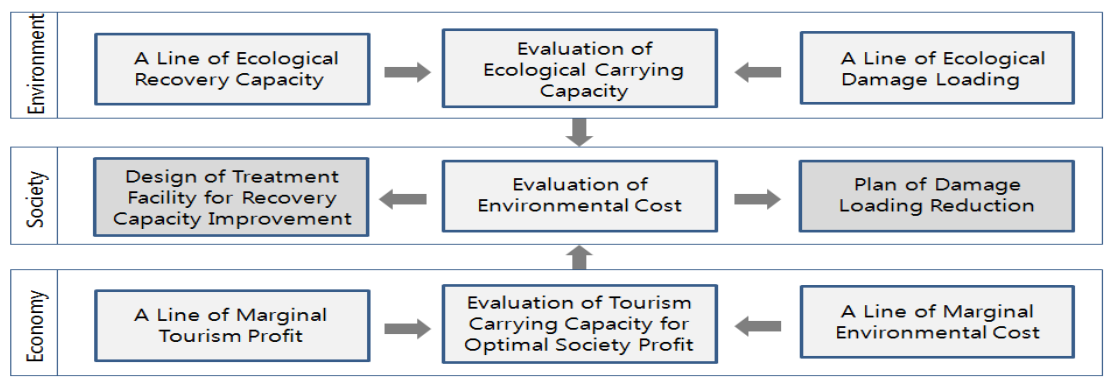

Figure 6: The determination process for the tourist carrying capacity of a virtuous cycle. 


\section{Conclusions}

This study has proposed a combined system of ECCL(ecological carrying capacity limit) model and MCCL(market carrying capacity limit) model as a means to establish a more scientific and systematic sustainable coastal ecological tourism development. In order to calculate the ECCL, 1) the ecological recovery capacity curve, and 2) the ecological damage capacity curve are needed to develop in advance, and in order to calculate the MCCL, 1) the marginal tourism profit curve, and 2) the marginal environmental goods cost curve are also needed.

Through an environment economic model, this study has proposed the fact that a number of tourists that socially provide the greatest net profit exists, with the assumption that the market principle is applied, based on the concept of environmental goods. Furthermore, a method of enhancing restricting carrying capacity has been proposed with the artificial improvement of ecology environmental recovery capacity and reduction of ecological damage capacity with the use of the cost of environmental goods. In other words, the accommodation of tourists that is ecologically and environmentally sustainable, and is also an environmentally and economically virtuous cycle can be achieved.

However, a cautious decision is needed in artificially extending the ELCC as problems difficult to control, such as diverse damage on ecospecies, secondary environmental problems, and limitation in management. This study is proposing a model that calculates the limitation market carrying capacity concerning the environment economic aspect, and a model that calculates the ecology environmental restrictive ecology carrying capacity, based on which the environmental impact assessment (EIA) system and the economic net profit assessment (EPA) system has been proposed as a linked methodology that becomes the basic assessment process for development policies that activate coastal tourism industry. The environmental impact assessment system is formed of the D-P-S-I-R system and the economic net profit assessment composed in a similar manner is formed of D-B-M-P-R system.

Accordingly, harmony is achieved for the sustainability of environmental preservation and the economy in the $\mathrm{S}$ (state) stage of the environment and the $\mathrm{M}$ (market) stage of the economy through sustainability analysis that collectively assesses the continuous and simultaneous achievements of environment preservation and economic profit, unlike existing environmental assessments. Therefore, they become methodologies that assess the sustainability of development plans by scientifically and systematically considering the environment as well as the economy, in a manner that corresponds with sustainable tourism development and by avoiding the contradiction that is applied on the direct assessment of the tourism development industry by existing environmental assessors. 


\section{References}

[1] Lück, M. The Encyclopedia of Tourism and Recreation in Marine Environments. Wallingford, UK: CABI, 2008.

[2] Manning, T. Indicators of Tourism Sustainability. Tourism Management, 20(1), pp. 3-6, 1999.

[3] Manning, R. E. Parks and Carrying Capacity: Commons without Tragedy. Washington, D.C.: Island Press, 2007.

[4] Orams, M. Marine tourism: Development, impacts, and management. London: Routledge, 1999.

[5] Marques, J. C., Basset, A., Brey, T. and Elliott, M., The ecological sustainability trigon-a proposed conceptual framework for creating and testing management scenarios. Mar. Pollut. Bull., 58, pp. 1773-1779, 2009.

[6] Ryan, C. Researching Tourist Satisfaction: Issues, Concepts, and Problems. London: Routledge, 1995.

[7] Lee, S.M., Development strategy for a sustainable nerve cell type tourism site: Focusing on the case of the Seolak national park (in Korean). Corporate Management Study, 19(2), pp. 237-251, 2011.

[8] Lee, S. Carrying capacity of sustainable tourism based on the balance concept between ecological damage loading and recovery capacity. Journal of Coastal Research, SI(64), pp. 1297-1301, 2011.

[9] Pigou, A.C. The Economics of Welfare, Macmillan: London, 1920.

[10] Meadows, E.D., Meadows, D.L., Randers, J., and Behres III, W.W. The Limit to Growth, New York: University Books, 1972.

[11] Adams, W. M. The future of sustainability: Re-thinking environment and development in the twenty-first century. Report of the IUCN Renowned Thinkers Meeting, pp. 29-31, 2006. 